\title{
Acknowledgements and Thanks
}

This book has been building in my brain for over 15 years, as I spent time with hundreds of families trying to raise bilingual children and listened to their stories, concerns and questions. Each unique family added to my own understanding of family language planning, and is in some way a part of this book. I thank them all for their confidence in me, and their willingness to share their stories with me.

My own children have been a part of the process, and I thank them for sharing their thoughts and opinions about languages and languaging along the way. Despite the best professional knowledge of 'what I should be doing', I still haven't always got it right with my own children, for which I ask their forgiveness.

And to my sister Erin, who is my greatest cheerleader in my writing, as well as being my time-keeper, coach and copy-editor, I couldn't do it without you. When do we start the next one?

Eowyn 